\title{
Auditory discrimination learning in chicks after exposure to auditory and visual stimuli
}

\author{
M. SOSENKO PETRO, P. J. CAPRETTA, and A. J. COOPER \\ Miami University, Oxford, Ohio 45056
}

\begin{abstract}
Bateson and Chantrey (1972) have shown a retardation of visual discrimination learning in chicks previously exposed to the discriminanda. They explained their results in terms of an imprinting mechanism whereby a young bird learns the various characteristics of an object and classifies them together. In the present study, chicks were exposed to $390 \mathrm{~Hz}, 295 \mathrm{~Hz}$, 390 and $200 \mathrm{~Hz}$, or "no sound" together with a flashing blue light. They were then required to learn to discriminate between $390 \mathrm{~Hz}$ and $200 \mathrm{~Hz}$, with the light as reinforcer. There was no indication of classification together of the auditory stimuli or the auditory and visual stimuli. Few chicks, regardless of prior experience, learned the discrimination. Explanations for the inability to learn are proposed.
\end{abstract}

Bateson and Chantrey (1972) and Chantrey (1972, 1974) have reported that chicks exposed to two visual stimuli and later required to discriminate between them learn to do so less rapidly than chicks not given such exposure. According to Chantrey (1972), the chick "classifies together" the stimuli, treating them as representing the same object seen from different views. Although the range of conditions in which the phenomenon occurs remain to be worked out [Stewart, Capretta, Cooper, and Littlefield (1977) were only able to demonstrate retardation under conditions very similar to those of Bateson and Chantrey's study], classification together is a concept of potential importance for understanding the nature of perceptual development and its effects on behavioral plaşticity.

The present study was designed to investigate the effects of preexposure to auditory and visual stimuli on later auditory discrimination in chicks.

\section{METHOD}

Subjects were 89 Shaver Starcross Leghorn chicks obtained as hatchlings from Martin's Hatchery, Gettysburg, Ohio. They were reared in individual cages $(26 \times 27 \times 25 \mathrm{~cm})$ in a constantly illuminated (two 100-W ceiling bulbs), humidified room maintained at $33^{\circ} \mathrm{C}$. The ambient noise level was $48 \mathrm{~dB}$, as measured by a 1558-BP octave noise-band analyzer.

The exposure apparatus was an alleyway $(188 \times 16.5 \times 31 \mathrm{~cm})$ painted flat gray, with a wire-mesh floor. At either end was a blue cylinder and a $6.99-\mathrm{cm}$ radio speaker. The cylinders $(17.8 \times 8.3 \mathrm{~cm}$ diam) were of translucent plastic covered with blue acrylic film. Each contained a 15 -W bulb that could be made to flash (1 flash/1.5 sec). The cylinder and adjacent speaker at each end were wired to operate together.

Three sounds were used during exposure: pure-tone frequencies of 390,200 , and $295 \mathrm{~Hz}$. They were produced by a Grason-Stadler 1285 noise generator and were recorded on tape. Each sound consisted of .5 -sec pulses occurring at 3- to 4-sec intervals and at an intensity of 62-68 dB. Two tape players could be fed into either speaker, so that two tones would be emitted alternately from the same speaker. The exposure room was dimly lighted ( $25-\mathrm{W}$ bulb) and maintained at $27^{\circ} \mathrm{C}$. Ambient noise level in this room was $45 \mathrm{~dB}$.
The discrimination apparatus consisted of a rectangular plywood box $(99 \times 31 \times 36 \mathrm{~cm})$ painted flat gray, with a wiremesh floor. A blue cylinder and speaker (similar to those in the exposure apparatus) were located in diametrically opposed corners. A tape player fed into each speaker, and either cylinder could be illuminated. An indirect light source faintly illuminated the apparatus. The room was maintained at $27^{\circ} \mathrm{C}$, and ambient noise was at $45 \mathrm{~dB}$.

Subjects were randomly assigned to one of four exposure conditions, $390 \mathrm{~Hz}, 390$ and $200 \mathrm{~Hz}, 295 \mathrm{~Hz}$, and "no sound." Exposure lasting $30 \mathrm{~min}$ was given at approximately 18, 30, and $42 \mathrm{~h}$ posthatching. The subjects were placed individually in the center of the alleyway; one cylinder was illuminated and the appropriate sound was turned on. Ten seconds after the chick approached a line $10 \mathrm{~cm}$ from the light, that light and sound were extinguished, and those opposite were turned on. This was repeated as often as the chick approached either end. (If, after $10 \mathrm{~min}$, the subject had not approached, the light was switched from end to end to attract it.)

The number of approaches during the exposure session was recorded. Subjects making at least 10 approaches during Session 3, or at least 20 in Sessions 1 and 2 and at least 6 in Session 3, were trained in the discrimination task.

Beginning at approximately $60 \mathrm{~h}$ posthatching, subjects were trained to discriminate between the 390 and $200-\mathrm{Hz}$ sounds, with the flashing blue light to which they had imprinted as reinforcement for a correct choice. Half the chicks were rewarded for approaching the $200-\mathrm{Hz}$ sound, half for approaching the $390-\mathrm{Hz}$ sound. Table 1 shows the treatment groups. Each chick was placed individually near one of the blue cylinders in the discrimination apparatus. The cylinder was then illuminated

Table 1

Treatment Groups

\begin{tabular}{llcc}
\hline & & \multicolumn{2}{c}{ Discrimination } \\
\cline { 3 - 4 } Group & \multicolumn{1}{c}{ Exposure } & Rewarded & $\begin{array}{c}\text { Non- } \\
\text { rewarded }\end{array}$ \\
\hline $390-390$ & $390 \mathrm{~Hz}$ & 390 & 200 \\
$390-200$ & $390 \mathrm{~Hz}$ & 200 & 390 \\
Both-390 & $390 \mathrm{~Hz}$ and $200 \mathrm{~Hz}$ & 390 & 200 \\
Both-200 & $390 \mathrm{~Hz}$ and $200 \mathrm{~Hz}$ & 200 & 390 \\
$295-390$ & $295 \mathrm{~Hz}$ & 390 & 200 \\
$295-200$ & $295 \mathrm{~Hz}$ & 200 & 390 \\
None-390 & "No Sound" & 390 & 200 \\
None-200 & "No Sound" & 200 & 390 \\
\hline
\end{tabular}


and allowed to flash for $30 \mathrm{sec}$. The chick was then removed from the apparatus for $30 \mathrm{sec}$. This procedure was repeated at the other cylinder. The chick was then removed from the apparatus for $30 \mathrm{sec}$, then replaced in its center. The two tape players were started together so that the $200-$ and $390-\mathrm{Hz}$ sounds were heard from their respective speakers simultaneously for $30 \mathrm{sec}$, during which time the chick could respond. During this time, a correct response (approaching to within $10 \mathrm{~cm}$ of the "correct" sound) was rewarded by the illumination of the adjacent cylinder for $10 \mathrm{sec}$. If the subject had not responded by the end of the $30-\mathrm{sec}$ period, the cylinder was illuminated for $10 \mathrm{sec}$. After each trial, the chick was returned to a holding cage for a $30-\mathrm{sec}$ intertrial interval. Each subject received 10 trials/day for a maximum of 8 days. The position of the correct sound was randomly alternated over trials. Criterion for learning was 8 correct responses out of any 10 consecutive trials. Additionally, it was noted whether the chick faced or moved partially toward the correct sound.

\section{RESULTS}

Of the 89 subjects, only 42 reached criterion for training in the exposure session. Table 2 summarizes the results of the discrimination training. The Kruskal-Wallis analysis of variance revealed no differences between the groups $[H(7)=9.11, p>.05]$. Many of the chicks failed to learn the discrimination in the 80 trials allowed; these were given the score of 80 .

Reexamination of the data, and scoring as correct trials in which the chicks merely faced in the correct direction, also revealed no intergroup differences. Analyzing across days, a main effect was seen $(F=3.56$, $\mathrm{p}<.0014)$. A Newman-Keuls test showed a significant increase in the frequency of correct facing from Day 1 to Day $3(\mathrm{q}=4.99, \mathrm{p}<.01)$ and a decrease from Day 3 to Day $5(\mathrm{q}=4.29, \mathrm{p}<.05)$.

The number of approaches to the light during exposure correlated significantly with the number of discrimination trials to criterion $(\mathrm{r}=-.36, \mathrm{t}=-2.44$, $\mathrm{p}<.01$, one-tailed). The more approaches a chick made, the fewer trials it needed to reach criterion in the learning task.

Table 2

Discrimination Learning

\begin{tabular}{lcccccc}
\hline & & \multicolumn{2}{c}{$\begin{array}{c}\text { Trials to } \\
\text { Criterion }\end{array}$} & & \multicolumn{2}{c}{$\begin{array}{c}\text { No. Reaching } \\
\text { Criterion }\end{array}$} \\
\cline { 3 - 4 } Group & N & WF & F & & WF & F \\
\hline $390-390$ & 6 & 80.0 & 80.0 & & 0 & 0 \\
$390-200$ & 6 & 63.0 & 61.8 & & 2 & 3 \\
Both-390 & 6 & 74.0 & 66.2 & & 1 & 2 \\
Both-200 & 6 & 54.0 & 54.3 & & 4 & 4 \\
$295-390$ & 6 & 61.0 & 54.3 & & 3 & 4 \\
$295-200$ & 6 & 52.4 & 51.8 & & 3 \\
None-390 & 3 & 65.3 & 49.0 & & 1 & 2 \\
None-200 & 4 & 80.0 & 67.5 & & 0 & 1 \\
\hline
\end{tabular}

Note $-F=$ facing; $W F=$ without facing (see text for explanation).

\section{DISCUSSION}

According to the "classification-together" hypothesis, the chicks exposed to both the $200-\mathrm{Hz}$ and the $390-\mathrm{Hz}$ sounds might have been expected to learn to discriminate them less readily than those exposed either to $295 \mathrm{~Hz}$ or to "no sound." If classification together occurs across modalities, then the chicks exposed to $390 \mathrm{~Hz}$ might subsequently find it difficult to associate the light with the $200-\mathrm{Hz}$ sound, whereas those exposed to $390 \mathrm{~Hz}$ and trained to $390 \mathrm{~Hz}$ should find the task easier. None of these expectations, however, was confirmed.

Our failure to show differential effects of exposure conditions on later learning might have cast doubt on the generality of the "classification-together" phenomenon had it not been for the small number of chicks reaching criterion in all groups. This being the case, no evaluation of the hypothesis can be made as a result of this study, although some possible explanations for the present results can be put forward. It is possible that frequency is not a salient cue for learning to discriminate sounds. Tones of less than $400 \mathrm{~Hz}$ elicit following, while those of greater than $400 \mathrm{~Hz}$ elicit "distress" calls (Collias, 1952). Perhaps most chicks merely differentiate high- and lowfrequency sounds. It is not known how (or if) chicks identify their mothers' calls from those of other hens.

Another possible explanation for the large numbers of chicks not learning could be that the flashing blue light was an ineffective reinforcer. Bateson and Reese (1969) have shown a flashing-light imprinting stimulus to have reinforcing properties, but the negative correlation between approaches and trials to criterion suggests that for many animals the light was not a potent imprinting stimulus and/or reinforcer.

Bateson and Chantrey's (1972) classification-together hypothesis relates to the development of perception and of associative processes in chicks. Our investigation is confounded by factors relating to these. It may be difficult to separate "figure from ground" sufficiently to manipulate conditions independently of the phenomenon in order to investigate its characteristics.

\section{REFERENCES}

Bateson, P. P. G., \& Chantrey, D. F. Retardation of discrimination learning in monkeys and chicks previously exposed to both stimuli. Nature, 1972, 237, 173-174.

Bateson, P. P. G., \& Reese, E. P. The reinforcing properties of conspicuous stimuli in the imprinting situation. Animal Behaviour, 1969, 17, 692-699.

Chantrey, D. F. Enhancement and retardation of discriminanda. Journal of Comparative and Physiological Psychology, $1972,81,256-261$.

Chantrey, D. F. Stimulus preexposure and discrimination learning by domestic chicks: Effect of varying inter-stimulus time. Journal of Comparative and Physiological Psychology, 1974, 87, 517.525.

Collias, N. E. The development of social behavior in birds. Auk, 1952, 69, 127-159.

Stewart, D. J., Capretta, P. J., Cooper, A. J., \& LITTLEFIELD, V. M. Learning in domestic chicks after exposure to both discriminanda. Journal of Comparative and Physiological Psychology, 1977, 91, 1095-1109.

(Received for publication August 16, 1978.) 